\title{
Melanosis peritonei in pregnancy: a case report and review of literature
}

\author{
Dimple Madhukar Jamkhandi • Pranay Gaikwad • \\ Daisy Singh • Kuryan George
}

Received: 11 February 2013 / Accepted: 30 October 2013 / Published online: 13 November 2013

(C) Springer-Verlag Berlin Heidelberg 2013

Keywords Cysts $\cdot$ Laparotomy $\cdot$ Melanosis peritonei ·

Peritoneal melanosis · Pregnancy

\section{Introduction}

Peritoneal melanosis is a rare condition characterized by pigment deposition in the peritoneum. Benign peritoneal melanosis may occur in association with other congenital cystic conditions such as ovarian dermoid, peritoneal, enteric duplication cysts, or even gastric triplication. We report the case of melanosis peritonei found during pregnancy diagnosed at the time of cesarean section for fetal distress.

\section{Case report}

A 20-year-old consanguineously married second gravida with a previous spontaneous abortion at 12 weeks, presented with features suggestive of pre-term labor pains and fetal distress at the 35th week of gestation. Her height was $140 \mathrm{~cm}$ and the body mass index was 21.93 with no other known risk factors. She attended routine antenatal visits, which were unremarkable, but had no ultrasound screening. She underwent emergency cesarean section that was uneventful with delivery of a girl weighing $1.9 \mathrm{~kg}$ with Apgar score of 9 and 10 at 1 and $5 \mathrm{~min}$, respectively. Under the circumstances, the cause for the fetal distress remained unexplained. Per-operatively, the

D. M. Jamkhandi $(\bowtie) \cdot$ D. Singh $\cdot$ K. George

Department of Community Health and Development, Christian

Medical College, Vellore 632002, Tamil Nadu, India

e-mail: dimple@cmcvellore.ac.in

P. Gaikwad

Department of General Surgery Unit-1, Christian Medical College,

Vellore 632004, Tamil Nadu, India peritoneal cavity was found to contain blackish-green thick viscous fluid emanating from the region of the right iliac fossa with dark black pigmented patches elsewhere over the visceral peritoneum, the omentum, and right ovary (Fig. 1). The right ovary contained a solid cystic mass of $10 \times 6 \mathrm{~cm}$. The cystic mass was aspirated and on advice of a senior consultant from an attached tertiary hospital, a wedge biopsy from the rest of the mass was performed. Pathology revealed a cyst wall composed of fibrocollagenous tissue containing inflammatory granulation tissue with dense infiltrates of histiocytes, lymphocytes, plasma cells, and several melanin-loaded macrophages. These findings were suggestive of melanosis peritonei and a benign ovarian dermoid cyst. The patient was advised to undergo right salpingo-oopherectomy. On a clinical review at 8 months postpartum, both baby and mother are doing well.

\section{Discussion}

Melanosis peritonei is an extremely rare condition with only 13 previously reported cases in the English literature [1-3]. This is the first published case in pregnancy. The condition has to be differentiated from other pigmented lesions like endometriosis, hemosiderosis, melanoma, and lipofuscinosis affecting the peritoneum.

The condition, when not associated with any malignancy, almost exclusively affects young females (mean age 18.3 \pm 10.3 years; range: $0.5-28$ years) with only 1 of the 14 reported cases was male. It has also been observed in the elderly, but this was always in association with malignancy $[2,3]$.

Commonly involved organs include ovaries, peritoneum, omentum, appendix, enteric cyst, intestine, liver, and gall bladder. The condition is associated with ovarian lesions in $57 \%$ of the cases [1]. In the remainder, it was associated with gastrointestinal congenital conditions and very rarely, with metastatic melanoma (one case) and colonic malignancy 


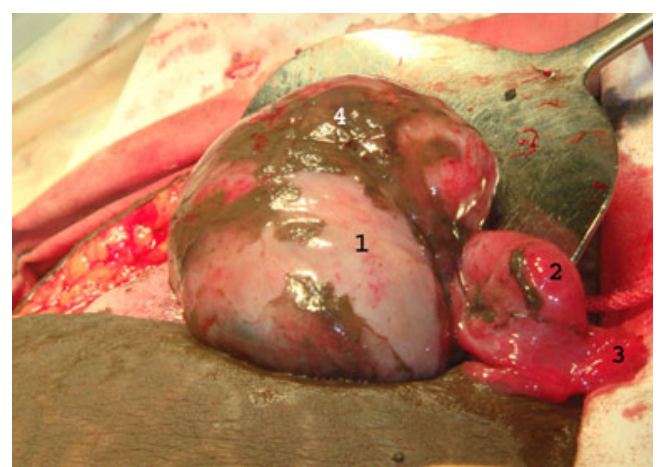

Fig. 1 Melanosis peritonei present in a pregnant lady: right ovarian dermoid cyst (1), swollen and distended right fallopian tube (2), right fimbriae (3), and melanosis of the peritoneal surfaces

(one case) $[2,3]$. The availability of a frozen section biopsy of the lesion may expedite the decision to proceed with a definitive surgical treatment in cases of benign lesions, which in our case, was not possible.

The pathogenesis of peritoneal melanosis, in particular, the origin of the pigment-producing cells is unclear. Among the recognized theories, spillage of pigment from ruptured ovarian teratomas is the most accepted [4]. The majority has indeed been observed in women with ovarian melanogenic tumors or ovarian teratomas in the reproductive age group. However, this theory is unable to explain the association of peritoneal melanosis with other conditions like peritoneal cyst, duplication cyst of the gastrointestinal tract, or colonic carcinoma. A possibility of multifocal occurrence has been suggested as melanin deposits have been noted on both inner and outer surfaces of the viscera. It has been suggested that peritoneal melanosis might occur independent of ovarian melanogenic tumors [5]. Further, the presence of melanocytes in the peritoneal cavity may be attributed to aberrant development from the neural crest cells as a result of either excessive migration of the neural crest cells toward the anterior abdominal wall or due to anomalous malposition of neural crest to the peritoneum before the 10th week [6,7]. Others have postulated that the esophageal mucosa, a common site for melanosis within enteric cysts, and a likely source of melanin, ruptures to peritoneal spaces [8]. The pigment could be derived from the breakdown of heme within dermoid cysts possessing a fully developed gastric wall with peptic ulceration [4]. These theories do not explain, however, the absence of melanophages in the mucosa of the enteric cyst, or unruptured cystic lesions. Lastly, it has been suggested that the pinched-off mesothelial remnants during development might be the progenitor cells evoking peritoneal melanosis [1].
On diagnosis, pathology will determine further management. Malignancy is to be excluded and suggested treatment for the dermoids is oopherectomy [9]. Metastatic peritoneal malignant melanoma has a very poor prognosis and can be treated with chemotherapy, with few survivors beyond 2 years of diagnosis [10].

\section{Conclusion}

Melanosis peritonei is an extremely rare condition that may be incidentally encountered during the course of a laparotomy. We did so at the time of cesarean section. It is usually associated with ovarian lesions. If not, it may point to other congenital anomalies and very rarely, to metastatic melanoma or colonic malignancy.

\section{Acknowledgments None.}

Conflicts of interest None.

\section{References}

1. Kim NR, Suh YL, Song SY, Ahn G (2002) Peritoneal melanosis combined with serous cystadenoma of the ovary: a case report and literature review. Pathol Int 52(11):724-729

2. Kim SS, Nam JH, Kim SM, Choi YD, Lee JH (2010) Peritoneal melanosis associated with mucinous cystadenoma of the ovary and adenocarcinoma of the colon. Int J Gynecol Pathol 29(2):113-116

3. Lim CS, Thompson JF, McKenzie PR, McCarthy SW, Scolyer RA (2012) Peritoneal melanosis associated with metastatic melanoma involving the omentum. Pathology 44(3):255-257

4. Jaworski RC, Boadle R, Greg J, Cocks P (2001) Peritoneal "melanosis" associated with a ruptured ovarian dermoid cyst: report of a case with electron-probe energy dispersive $\mathrm{x}$-ray analysis. Int $\mathrm{J}$ Gynecol Pathol 20(4):386-389

5. Drachenberg CB, Papadimitriou JC (1990) Melanotic peritoneal cyst. Light-microscopic and ultrastructural studies. Arch Pathol Lab Med 114(5):463-467

6. Nada R, Vaiphei K, Rao KL (2000) Enteric duplication cyst associated with melanosis peritonei. Indian J Gastroenterol 19(3):140-141

7. Le Douarin NM, Kalcheim C (1999) The neural crest: source of the pigment cells. In: Le Douarin NM, Kalcheim C. The Neural Crest. 2nd ed. Cambridge University Press, Cambridge. pp 261-263

8. Jung YC, Chen CJ, Tzeng CC (1996) Melanosis peritonei associated with enteric duplication cyst. A case report. Am J Surg Pathol 20(2): 181-186

9. Ayhan A, Bukulmez O, Genc C, Karamursel BS, Ayhan A (2000) Mature cystic teratomas of the ovary: case series from one institution over 34 years. Eur J Obstet Gynecol Reprod Biol 88(2):153-157

10. Gao R, Liu NF, Sheng XG (2010) Malignant ovarian melanoma with extensive pelvic and peritoneal metastasis: a case report and literature review. Chin J Cancer 29(4):460-462 